\title{
Frontoethmoidal Mucocele with Unilateral Proptosis
}

\author{
${ }^{1} J$ yoti Singh, ${ }^{2}$ Haritosh Velankar, ${ }^{3}$ Yogesh Dabholkar, ${ }^{1}$ S harad Bhalekar \\ ${ }^{1}$ Lecturer, Department of ENT, Padmashree Dr DY Patil Medical College, Nerul, Navi Mumbai, Maharashtra, India \\ ${ }^{2}$ Professor and Head, Department of ENT, Padmashree Dr DY Patil Medical College, Nerul, Navi Mumbai, Maharashtra, India \\ ${ }^{3}$ Associate Professor, Department of ENT, Padmashree Dr DY Patil Medical College, Nerul, Navi Mumbai, Maharashtra, India
}

Correspondence: J yoti Singh, Lecturer, Department of ENT, C-102, Mahavir Drishty, Plot no. 04, Kharghar, Sector 12, Navi Mumbai-410210, Maharashtra, India, Phone: 9967543545/022-27745460, e-mail: jotthi@ yahoo.com

\section{ABSTRACT}

Frontoethmoidal mucocele can present with a multitude of different symptoms including ophthalmic disturbances. Though benign, they have a tendency to expand by thinning the bony walls. They displace and invade surrounding structures by pressure and bony resorption. If it invades the orbit and continues to expand, the mass may mimic the behavior of many benign growths arising primarily in the orbit. We report a case of a frontoethmoidal mucocele extending into the orbit. Clinically, the patient had an insidious onset of clinical presentation with no intracranial symptoms.

Keywords: Frontoethmoidal mucocele, Proptosis, Paranasal sinuses, Frontoethmoidectomy, Pott's puffy tumor.

\section{INTRODUCTION}

Mucoceles are slowly expanding cystic lesions with respiratory epithelium containing mucus most commonly affecting the frontal and ethmoidal sinuses. They are caused by obstruction of sinus ostium. The occlusion of the ostia may be secondary to congenital anomalies, allergy, infection, and trauma, surgical intervention in the nose and neoplasm or metastatic tumor. ${ }^{1}$ Even benign, they have a tendency to expand and they displace and destroy structures by pressure and bony resorption.

\section{CASE PRESENTATION}

A 77-year-old male patient was suffering from left sided proptosis and pain around the left eye since 2 years (Fig. 1). On examination, patient had restricted eye movements and diplopia. Pupils were reactive, visual acuity was $6 / 9$ and color vision was normal. Fundoscopic examination revealed a minimal papilledema. A nterior rhinoscopy was normal. On enquiry, there was a history of head injury 10 years back with an episode of epistaxis that time for which he took conservative treatment. Coronal computerized tomography showed an abnormal well defined hyperdense nonenhancing lesion measuring approximately $4.8 \times 3.8 \times 3.8 \mathrm{~cm}$ in the superior portion of the globe in the extraconal compartment (Fig. 3). The lesion was causing expansion and pressure erosion of the left frontal sinus, left frontoethmoid recess with significant attenuation of the anterior wall of the left frontal sinus and the roof and superomedial orbital walls. The lesion was causing proptosis of the left globe and abutting and compressing the left superior rectus-levator palpebrae superioris complex displacing it inferiorly and the left lateral rectus muscle inferomedially. The clinical and radiological findings were most likely suggestive of frontoethmoidal mucocele. Endoscopic sinus surgery was planned and anterior ethmoidectomy was performed. Frontal recess area could not be visualised even with the hel $p$ of a $45^{\circ}$ nasal endoscope. A probe was passed in frontal recess area but it was found to be completely obliterated and no communication was found between the nose and the frontal sinus. Hence an external approach was carried out with an extended L ynch-Howarth incision. There was a defect found in the orbital roof. Frontal mucocele was excised and frontonasal drainage established by making a hole in the floor of the frontal sinus with the help of a drill and placing

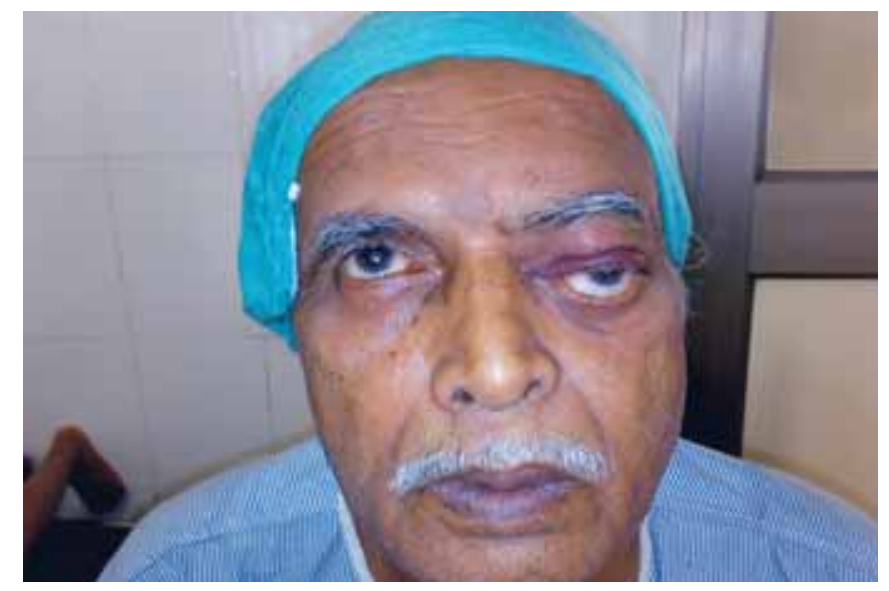

Fig. 1: Preoperative picture 


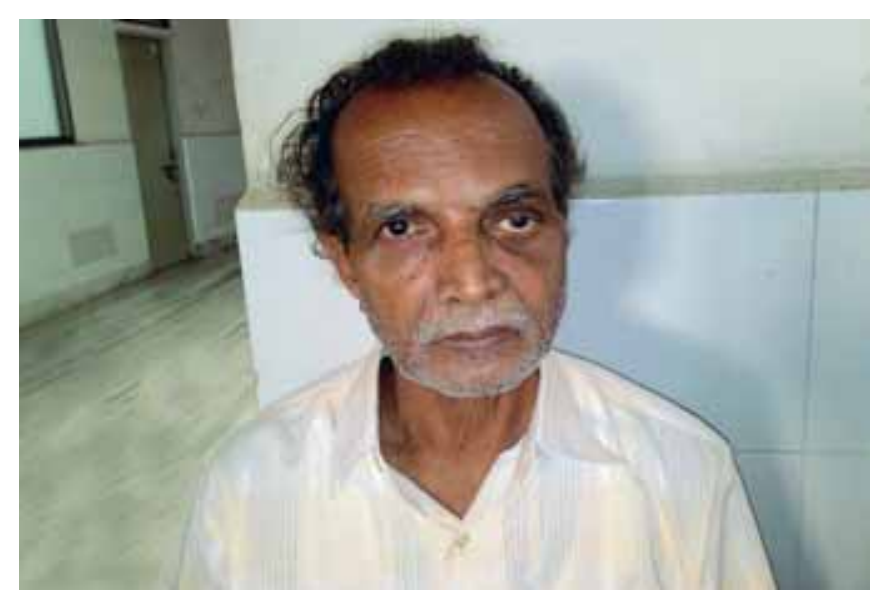

Fig. 2: 6-week postoperative picture

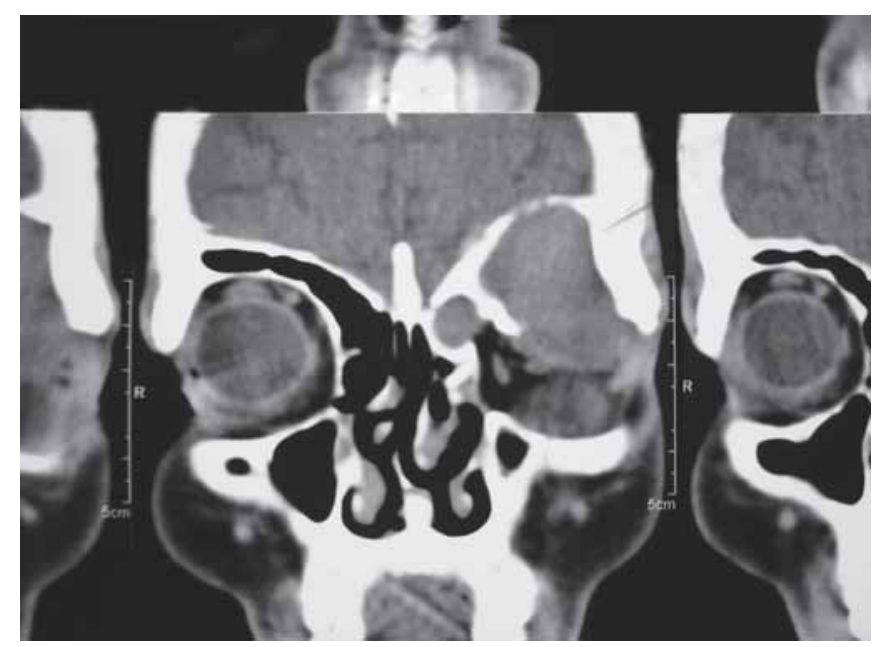

Fig. 3: CT PNS coronal section of the patient

a portex tube through it. The wound was sutured in layers. The tube was removed after 4 weeks. Eye movements returned to normal and papilledema resolved (Fig. 2). There was no recurrence in one year follow-up.

\section{DISCUSSION}

The term mucocele was introduced by Rollet in 1896 and the first histopathological description was made by Onodi in 1901. The exact mechanism underlying the development of a mucocele of the paranasal sinuses is unknown. M ost of the authors believe this cystic dilatation of the sinuses to be secondary to obstruction of the nasal ostium as a result of recurrent bouts of inflammations, trauma, or repeated surgery in and around the nasal cavity and adjacent sinuses. ${ }^{2,3}$ It is very important to suspect post-traumatic obliteration of osteum which eventually may lead mucocele formation as it happened in our case. Sites of occurrence of mucoceles are the frontal sinus, anterior ethmoidal sinus, maxillary sinus and rarely the posterior ethmoidal sinus and sphenoidal sinus. ${ }^{4}$ They may occur at any age, but most of them are seen between the fourth and seventh decades. They are equally common in both sexes. Mucoceles tend to expand, remodel and reabsorb bony walls of affected paranasal sinuses, changing their integrity and occasionally affecting the neighboring structures, such as the orbit and the intracranial cavity. ${ }^{3}$ L und et al implicated various cytokines and inflammatory mediators as being responsible for the remodelling and resorption of the bone. ${ }^{5}$ Since frontoethmoid mucoceles expand in the direction of least resistance they causes outw ard and downward displacement of the globe and are often associated with a palpable mass in the superonasal and medial canthal region. ${ }^{6}$ The expanding mass lesion may cause proptosis, restriction of eye movements, diplopia, visual loss, retro-orbital pain or headache. CT is the preferred mode of imaging for paranasal pathology as it gives evidence of bone involvement, assesses intracranial and/or orbital extension and supports surgical planning. On CT scan, the mucoceles usually appear as homogeneous, low density, nonenhancing soft tissue masses causing expansion of the involved sinus and erosion of the adjacent orbital walls with protrusion of the mass into the orbit. M any surgical approaches to frontal mucoceles have been described. They may be either endoscopic, external approach or combined.

External approach is made through frontoethmoidectomy (Lynch's procedure) or by osteoplastic flaps with or without frontal sinus obliteration and total excision of mucosa. In our case, mucocele was removed by combined approach (ESS+ external frontoethmoidectomy). The combined approach has the precision of endoscopic surgery as well as direct exposure of entire sinus, especially in case of frontal sinus, providing complete removal of mucocele and preventing blind curettage.

A controversy exists whether or not the entire mucosal lining of the mucocele should be excised. The current trend is to conduct a functional, minimally invasive and a low morbidity procedure with sinonasal endoscopic surgery with marsupialization and abundant drainage of the lesion, preserving the epithelium. ${ }^{2,3}$ In our case, we have removed the mucocele completely and tried to preserve normal mucosa as much as possible.

\section{CONCLUSION}

Frontoethmoidal mucocele are benign and with good outcome if treated timely. Early recognition and management is of paramount importance because they can cause local, orbital or intracranial complications. The objective of the therapy is to remove the cyst completely and restore the drainage from the occluded sinus into the nostril irrespective of the approach either endoscopic or external or combined. 


\section{REFERENCES}

1. Molteni G, Spinelli R, Parigatti S, Colombo L, Ronchi P. $V$ oluminous frontoethmoidal mucocele with epidermal involvement. Surgical treatment by coronal approach. Acta Otolaryngol Ital 2003;23:185-90.

2. Chiarini L, Nocini PF, B edodni A, et al. Intracranial spread of a giant frontal mucocele: $C$ ase report. B ritish J ournal of Oral and M axillofacial Surgery 2000;38:637-40.
3. Hurley DB, Javer AR, Kuhn FA, Citardi MJ. The endoscopic management of chronic frontal sinusitis associated with frontal sinus table erosion. A m J Otolaryngology 2000;114:233-36.

4. Lioyd G, Lund VJ, Savy L, Howard D. Radiology in focus. J Laryngol Otol 2000;92:1075-82.

5. L und V J, Henderson B, Song Y. Involvement of cytokines and vascular adhesion receptors in the pathology of frontoethmoidal mucoceles. A cta Otolaryngol 1993;113:540-46.

6. Tasman W, Jaegar EA. Duane's clinical ophthal mology. $\mathrm{New}$ York: JB Lippicott Co 1994;2:3-7.

\section{Editorial Inputs}

\section{Frontoethmoidal Mucocele with Unilateral Proptosis}

\section{${ }^{1}$ Bachi T Hathiram, ${ }^{2}$ Vicky S Khattar}

${ }^{1}$ Professor and Head, Department of ENT and Head and Neck Surgery, Topiwala National Medical College and BYL Nair Charitable Hospital Mumbai, Maharashtra, India

${ }^{2}$ Assistant Professor, Department of ENT and Head and Neck Surgery, Topiwala National Medical College and BYL Nair Charitable Hospital Mumbai, Maharashtra, India

Mucoceles in the region of the frontal recess can be ethmoidal, frontoethmoidal or supraorbital. While most of them may present in a similar fashion with proptosis, downward and outward displacement of the eyeball and visual disturbances, it is vital to read the serial CT scan images of such patients to determine the exact 'cul prit' sinus, so as to allow for a successful endoscopic marsupialization.

Below is the CT scan image of one such patient with left sided proptosis and visual loss of gradual onset and

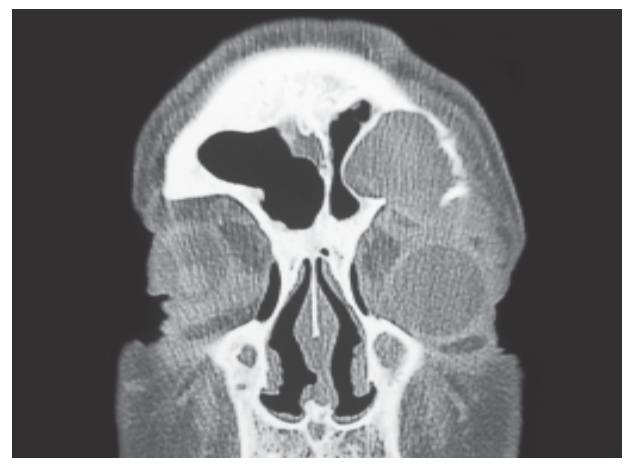

Fig. 1

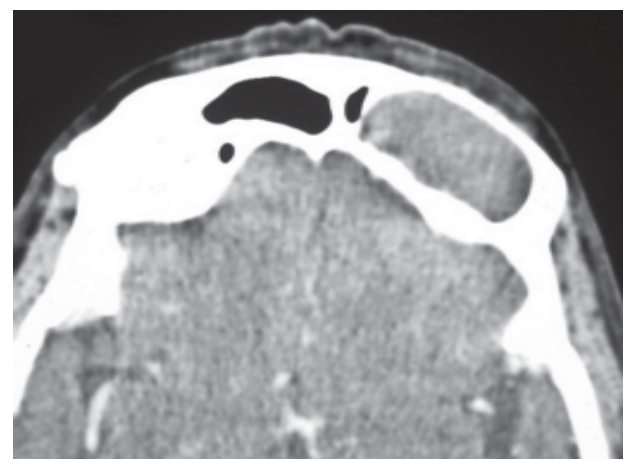

Fig. 2 progress. The CT scan images revealed it to be from a supraorbital cell.

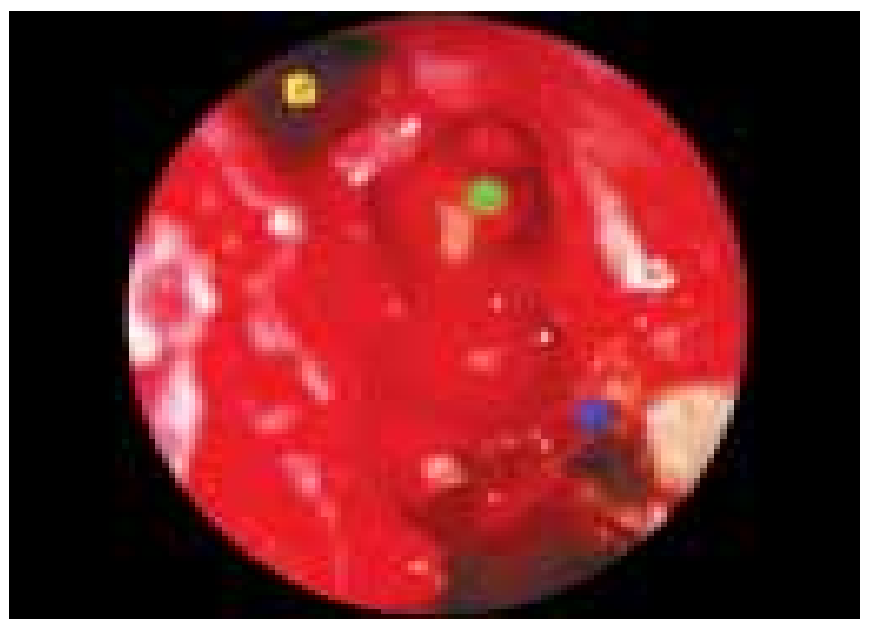

Fig. 3

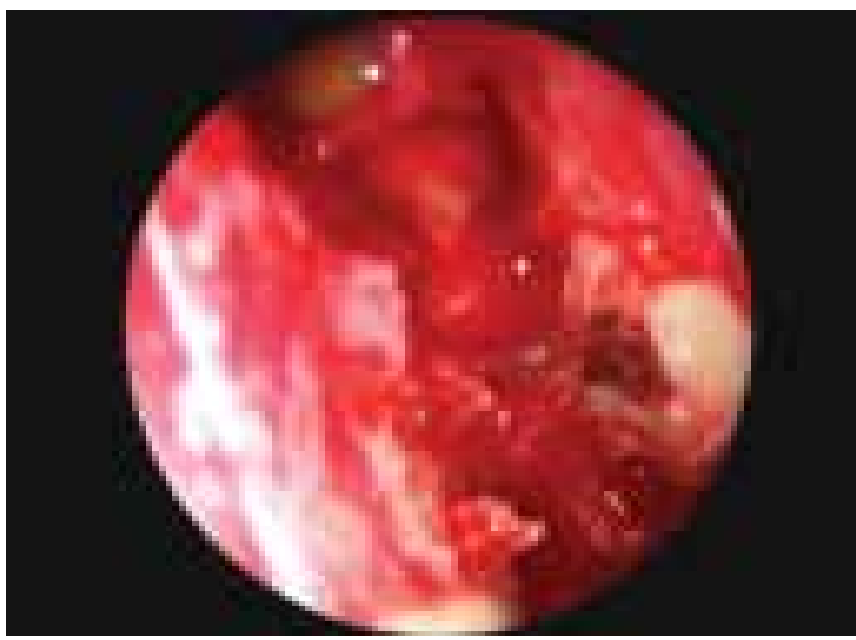

Fig. 4 
Here, the medially compressed let frontal sinus can be appreciated. Thus, the anteriormost coronal images at the level of the frontal beak would help one to determine the origin of the mucocele.

The 'clincher' for diagnosis w ould be the axial CT scan, which would show the lateral mucocele in a supraorbital cell, and a medial aerated frontal sinus.

This has therapeutic implications. The mucocele can be marsupialized by either directly approaching the supraorbital cell, behind the frontal sinus endoscopically, or dividing the thin partition between the frontal sinus and the mucocele as can be appreciated the axial CT scan. This would result in the supraorbital cell draining into the frontal sinus and recess. A $n$ inability to diagnose this relation could result in a failure to endoscopically manage this condition.
A $n$ intraoperative endoscopic image of the same patient showing a widely opened left frontal recess. One can appreciate the posterior table of the frontal sinus (green dot), the medially compressed frontal sinus (yellow dot). In an overzeal ous attempt to ' $f$ ind' the mucocele, the left anterior ethmoidal artery was accidentally damaged, and had to be dealt with a bipolar cautery. The cauterized vessel can be seen in the lower end of the image (blue dot).

The mucopus can now be seen emerging laterally and posteriorly from the supraorbital cell, which was marsupialized into the frontal sinus and recess.

Note: This case report was published in the 'A sian Journal of ENT' by the editors, in the issue Oct-Dec 2009;30-33- however, the images used for this discussion are different from those used for the case report. 